\title{
An approach to the management of patients with residual Cushing's disease
}

\author{
Lewis S. Blevins Jr. • Nader Sanai • \\ Sandeep Kunwar · Jessica K. Devin
}

Received: 11 November 2008/Accepted: 2 April 2009/Published online: 19 April 2009

(C) The Author(s) 2009. This article is published with open access at Springerlink.com

\begin{abstract}
The evaluation and management of patients with residual Cushing's disease is one of the more complex issues facing neurosurgeons and neuroendocrinologists in clinical practice. There is considerable controversy over several relevant issues such as the timing of the assessment of whether a patient is in remission, what biochemical parameters define remission, the most appropriate course of action to take after residual disease has been defined, etc. As a consequence of the controversies, treating physicians develop notions and fall into certain practice patterns based on evidence of varying levels, their anecdotal experiences, and information gleaned from scientific meetings. This practice pattern, we believe, constitutes the "art of medicine." We conducted a PubMed literature search to identify manuscripts containing data relevant to Cushing's disease, outcomes of various therapeutic modalities, and recurrences. Reference lists were used to identify additional relevant manuscripts. We focused our review on manuscripts
\end{abstract}

L. S. Blevins Jr. $(\bowtie) \cdot$ N. Sanai $(\bowtie) \cdot$ S. Kunwar

California Center for Pituitary Disorders, University of

California at San Francisco, 400 Parnassus Avenue,

Room A-808, San Francisco, CA 94143-0350, USA

e-mail: blevinsl@neurosurg.ucsf.edu

N. Sanai

e-mail: sanain@neurosurg.ucsf.edu

L. S. Blevins Jr. · N. Sanai · S. Kunwar

Department of Neurological Surgery, University of California at

San Francisco, San Francisco, USA

J. K. Devin

Department of Endocrine Neoplasia and Hormonal Disorders, University of Texas M.D. Anderson Cancer Center, Houston, TX, USA that included reasonably large series of patients, those reflecting the experience of pituitary centers and physicians recognized as experts in the field, and those papers felt to represent seminal contributions to the literature. Furthermore, trends in the evaluation and management of relevant patients have been incorporated by the senior author who has seen and evaluated over 750 patients with documented Cushing's syndrome over the past 18 years in clinical practice. An analysis of current evidence indicated that, despite advances in neurosurgical techniques and recent developments in adjuvant therapies, patients with residual Cushing's disease present significant management challenges to treating physicians. In this era, however, it is indeed possible to gain control of the hypercortisolism in most patients. Despite the wide variability in research methodology designed to collect relevant data, a step-wise approach to the management of these patients can be achieved. A logical step-wise approach to the evaluation of postoperative patients with Cushing's disease is essential. Patients with residual disease require the development of an individualized plan of management that takes into account numerous factors pertaining to status of disease, the experience of treating physicians, and available therapeutic modalities.

Keywords Cushing's disease - Transsphenoidal . Pituitary $\cdot$ Radiotherapy

\section{Introduction}

Patients with residual Cushing's disease after initial surgery present a wide variety of challenges to their healthcare team. After having gained experience with these fascinating patients, we have concluded that treating physicians 
must evaluate and manage patients with residual or recurrent Cushing's disease in a logical step-wise fashion. One must first verify the original diagnosis and then re-evaluate the status of the underlying disease. Thereafter, it is possible to outline an approach to subsequent management, including treatment of associated morbidities. Patients and their families require a great deal of support, education, and guidance in the decision-making processes regarding follow-up and treatment. This review is intended to provide an overview of our biased approach to these patients based on our experiences, some of the data gleaned from a review of the literature, and information derived from discussions with leaders in the field.

\section{The efficacy of transsphenoidal pituitary surgery in patients with Cushing's disease}

Transsphenoidal surgery is the initial treatment of choice for most patients with Cushing's disease. The principal goals of surgery include complete resection of the ACTHsecreting pituitary tumor, resolution of the hypercortisolemic state and its associated morbidities, and restoration of the normal dynamic function of the hypothalamicpituitary-adrenal axis. When possible, the pituitary gland should be spared so that patients do not require hormone replacement therapy.

Most of the published data regarding the outcomes of initial surgery are derived from retrospective case series $[1-3,6,10,13,14,22,27,31,36,37]$. These observations, while forming the basis of the knowledge we share with our patients, must be reviewed with the understanding that uniform criteria regarding the definitions of cure and recurrence have not been applied across published reports. This is in part due to the fact that, even amongst experts in the field, there is still disagreement as how to best distinguish between patients in remission and those with residual disease [8, 38-40]. Further, many of the available studies are not of sufficient duration to allow for recurrence in some patients with Cushing's disease.

Published series from experienced centers demonstrate that remission following initial surgery can be expected in $70-90 \%$ of patients with Cushing's disease caused by microadenomas. Remission is seen in 50-65\% of patients with macroadenomas (Tables 1,2). Recurrent hypercortisolism affects approximately $10 \%$ of patients with microadenomas and as many as $30 \%$ of patients with macroadenomas. While most recurrences occur within 5 years of surgery, some are not evident until a decade or more after an initially successful surgery. Thus, life-long follow-up with periodic reassessments is required even when patients are thought to have been cured.
Table 1 Published data regarding the outcomes of surgical therapy of all patients with Cushing's disease

\begin{tabular}{lrlll}
\hline First author & $\begin{array}{l}\text { Total \# } \\
\text { patients }\end{array}$ & $\begin{array}{l}\text { Remission } \\
(\%)\end{array}$ & $\begin{array}{l}\text { Recurrence } \\
(\%)\end{array}$ & $\begin{array}{l}\text { Mean } \\
\text { follow-up } \\
\text { (months) }\end{array}$ \\
\hline Invitti [14] & 288 & 69 & 17 & \\
Bochicchio [2] & 668 & 76 & 13 & 46 \\
Blevins [1] & 96 & 85 & 16 & 49 \\
Sonino [36] & 103 & 77 & 26 & 72 \\
Mampalam [22] & 216 & 79 & 5 & 46 \\
Swearingen [37] & 161 & 85 & 7 & 24 \\
Nakane [27] & 100 & 92 & 9 & 39 \\
Esposito [6] & 40 & 80 & 34 & 33 \\
Imaki [13] & 49 & 80 & 10 & 88 \\
Pereira [31] & 78 & 72 & 12 & 84 \\
Hammer [10] & 289 & 82 & 9 & 131 \\
\hline
\end{tabular}

Table 2 Published data regarding outcomes of surgical treatment of patients with Cushing's disease due to pituitary macroadenomas

\begin{tabular}{llllc}
\hline First author & $\begin{array}{l}\text { Total \# } \\
\text { patients }\end{array}$ & $\begin{array}{l}\text { Remission } \\
(\%)\end{array}$ & $\begin{array}{l}\text { Recurrence } \\
(\%)\end{array}$ & $\begin{array}{l}\text { Mean } \\
\text { follow-up } \\
\text { (months) }\end{array}$ \\
\hline Blevins [1] & 21 & 67 & 36 & 62 \\
Swearingen [37] & 17 & 65 & 18 & 104 \\
De Tommasi [3] & 37 & 68 & 12 & 42 \\
\hline
\end{tabular}

\section{Initial postoperative assessment of patients with Cushing's disease}

Several algorithms or approaches have been proposed to assess cortisol secretion in the immediate postoperative period in order to identify patients with persistent disease and to plan for immediate additional treatment $[6,8,13$, $31,39]$. Once again, there is no consensus regarding the definition and best means of identifying patients with residual Cushing's disease. It is clear, however, that patients with elevated postoperative serum cortisol concentrations and elevated urine cortisol excretion rates have had unsuccessful surgeries and require additional treatment.

We expect a period of transient adrenal insufficiency, lasting an average of 12 months, in patients who have had successful surgery. The adrenal insufficiency, also referred to as central adrenocortical insufficiency, is due to profound suppression of the hypothalamus and residual normal anterior pituitary corticotrophs by the pre-existing hypercortisolism. Patients who have normal cortisol levels and fail to develop adrenal insufficiency are presumed to have residual tumoral corticotrophs that are secreting sufficient amounts of ACTH to maintain adrenal function. However, 
Fig. 1 Salivary cortisol profiles in a patient with (a) Cushing's disease and (b) normal function of the hypothalamic-pituitaryadrenal unit
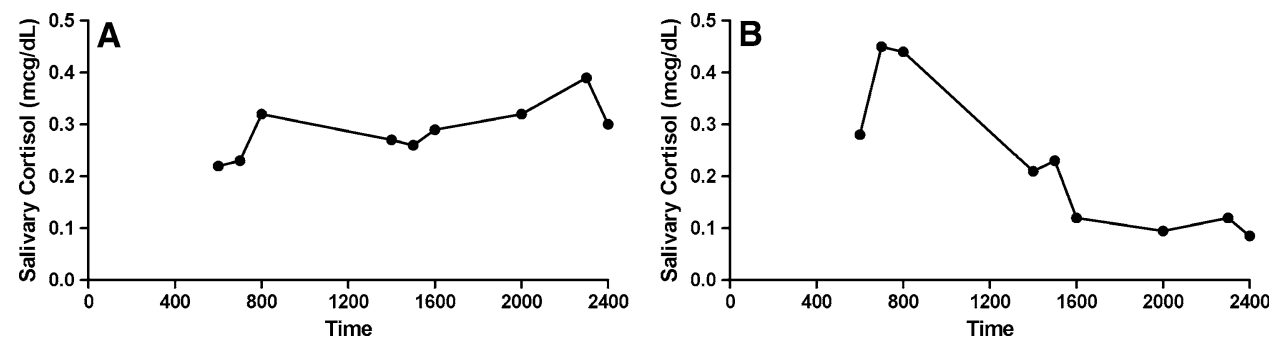

recurrent hypercortisolism is seen in only one-quarter of patients with normal postoperative serum cortisol levels [2]. In fact, recurrence is also seen in $4-11 \%$ of patients who develop central adrenocortical insufficiency after surgery $[2,13,40]$. Thus, a simple measurement of the serum cortisol level after surgery does not always indicate the presence or absence of disease.

Estrada et al. showed that patients in whom the diurnal variation in cortisol secretion has been restored to normal are far less likely to develop recurrent hypercortisolism (3\%) than those who have persistent abnormalities in the diurnal variation of cortisol secretion (50\%) [8]. We find this observation to be true in our practice and believe loss of diurnal variation to be the sine qua non of pathologic hypercortisolism. When it is unclear to us as whether or not a patient has residual or recurrent Cushing's disease we employ tests of salivary cortisol levels at 9 time points throughout the day to assess diurnal variation in our patients (Fig. 1). Others have suggested that suppression of cortisol secretion by dexamethasone is a reliable indicator of remission [23]. We have, however, managed several patients with suspected persistent or recurrent disease whose serum cortisol levels were suppressed to $<2 \mathrm{mcg} / \mathrm{dl}$ after administration of $1 \mathrm{mg}$ dexamethasone who went on to have overt evidence for recurrent disease. In several cases these patients had demonstrated abnormal diurnal variations in their salivary cortisol levels when their cortisol levels were "normal" and suppressible. Thus, we do not consider the suppression of cortisol levels following the administration of dexamethasone in postoperative patients to be evidence always in support of remission.

We find an immediate postoperative cortisol level to be useful only in identifying those patients with ongoing, flagrant hypercortisolism. These patients are usually obvious to treating physicians as they demonstrate continued impaired glycemic control, hypertension, and persistent plethora throughout the postoperative period. Caution is advised when considering additional treatment for those patients who have normal immediate postoperative cortisol levels, as only a proportion will indeed have residual disease in need of additional treatment [2]. We prefer to delay our formal comprehensive assessment of cortisol secretion until the first postoperative visit, scheduled for 6 weeks after initial surgery. We have found that this approach minimizes physician and patient frustration as well as the prescription of potentially unnecessary adjuvant therapy. We assert that cortisol levels obtained 6-12 weeks after surgery in patients with Cushing's disease are more useful for predicting the likelihood of long-term remission than serum cortisol levels obtained within 2 weeks of surgery. This approach is further supported by a review of the data of Toms et al. [38] illustrating cortisol levels reach their nadir several weeks after surgery.

\section{Evaluation of the reasons for surgical failure}

It is essential to consider several possible scenarios when faced with patients who have sufficient clinical and biochemical evidence of residual Cushing's disease (Tables 3, 4). Was the diagnosis of Cushing's disease, implicating the presence of an ACTH-secreting pituitary

Table 3 A logical approach to the postoperative evaluation of patients with suspected residual or recurrent Cushing's disease

Step 1 Confirm presence pathologic ACTH hypersecretion exists after surgery

Elevated Urine Free Cortisol on 2-3 occasions

Abnormal diurnal variation in serum or salivary cortisol levels

Abnormal Dex-CRH stimulation test

Substantiating clinical evidence

Step 2 Confirm preoperative diagnosis of ACTH-dependent hypercortisolism

Review data to determine if pathologic hypercortisolism was indeed present prior to surgery

Review preoperative MRI studies to determine if pituitary tumor was present

Step 3 Review histopathology for evidence of ACTH-producing pituitary tumor

ACTH-immunopositive lesion?

Crooke's Hyaline change present?

Step 4 Consider differential diagnosis

MRI to evaluate for pituitary tumor

Inferior petrosal sinus sampling if surgical pathology was negative

Overnight $8 \mathrm{mg}$ Dexamethasone suppression test to evaluate pathophysiology of ACTH excess

Octreoscan if ectopic ACTH secretion suspected 
Table 4 Potential causes of failed surgery in patients with Cushing's disease

\begin{tabular}{l}
\hline Incorrect preoperative diagnosis \\
\hline Syndrome of ectopic ACTH hypersecretion \\
Ectopic pituitary adenoma (cavernous sinus, suprasellar, stalk) \\
Corticotroph hyperplasia \\
Pseudo-Cushing's syndrome \\
Factitious Cushing's syndrome
\end{tabular}

Incomplete or failed tumor resection

Inexperienced neurosurgeon

Invasive disease

Negative MRI

Negative histopathology

tumor, correct? Patients with the occult syndrome of ectopic ACTH hypersecretion, and especially those with bronchial carcinoid tumors, often mimic, both clinically and biochemically, patients with ACTH-secreting pituitary tumors. In our experience, however, a significant portion of the patients who underwent exploration for a pituitary tumor yet were ultimately found to have the syndrome of ectopic ACTH hypersecretion had biochemistry suggestive of the correct diagnosis. Thus, a careful review of available test results is an essential step in the evaluation of patients who have failed surgery. In many cases, it is useful to repeat dynamic tests of the hypothalamic-pituitary-adrenal axis in order to better understand the pathophysiology of the hypercortisolism.

Review of the histopathology report is critical when evaluating patients in the postoperative period. Demonstration of an ACTH-secreting pituitary tumor in a patient who has persistent hypercortisolism can confirm that the preoperative diagnosis was correct and might suggest that removal of the tumor was incomplete. Microscopic evidence of invasion into surrounding structures has been demonstrated in $8 \%$ of patients with ACTH-secreting microadenomas and $62 \%$ of patients with ACTH-secreting macroadenomas [34]. Thus, it is not surprising that some patients will have residual disease or experience disease recurrence despite gross total resection of their pituitary tumors. In one series, the surgical failure rate was $26 \%$ in patients who did not have visible tumors on preoperative MRI scans of the sella [2]. By comparison, the failure rate was only $13 \%$ in patients who had a demonstrable tumor. The absence of confirmatory histopathology is associated with a higher rate of surgical failure $(47 \%)$ than when an ACTH-producing pituitary tumor is confirmed (17\%) [2]. The absence of Crooke's hyaline change within the resected pituitary tissue suggests that a preoperative diagnosis of hypercortisolism was perhaps incorrect [33].
Inferior petrosal sinus sampling with corticotropinreleasing-hormone stimulation, if not previously performed, may be indicated for those patients in whom an ACTH-secreting pituitary tumor was not identified at the time of surgery. We strongly advise the procedure when a review of the available endocrine data is not specific for the diagnosis of an ACTH-secreting pituitary tumor and especially when the data are thought to be consistent with the syndrome of ectopic ACTH hypersecretion.

Unfortunately, a significant proportion of transsphenoidal surgical procedures are still being performed by inexperienced neurosurgeons. Practice surveys have clearly illustrated that complication rates are higher following attempts at transsphenoidal surgery by relatively inexperienced surgeons compared with more experienced pituitary surgeons [32]. It is generally accepted that cure rates are higher in the hands of experienced surgeons. Thus, the skill of the operating neurosurgeon must be taken into account when evaluating and planning therapy for patients who have failed surgery.

\section{General approach to the management of patients with residual Cushing's disease}

Once a diagnosis of persistent Cushing's disease has been confirmed, one must consider treatment options in the context of the affected patient. Patients should be advised of the available treatments, the expected outcomes, risks, inconveniences, and costs so they can make informed decisions on how best to proceed. Ideal therapeutic strategies are directed at resolution of the hypercortisolism as well as control of the offending tumor. In many cases, however, these objectives must be dealt with independently. Despite the fact that there are numerous therapies for patients with residual or recurrent hypercortisolism, many will unfortunately never achieve complete remission of their disease. Additional goals of therapy include management of adverse consequences of therapy, such as hypopituitarism, and correction or control of the manifestations of hypercortisolism including hyperglycemia, hypertension, osteopenia, management of infections, etc.

\section{The efficacy of repeat pituitary surgery}

Repeat transsphenoidal surgery should be considered for all patients with residual Cushing's disease. Those with macroadenomas and an accessible tumor that is visible on MRI may benefit from additional decompression and the subsequent fall in ACTH and cortisol levels even though complete remission in these patients is uncommon following a second procedure $[1,3,20,32,37]$. We do not 
Table 5 Published data regarding outcomes of repeat surgery in patients with Cushing's disease

\begin{tabular}{lclc}
\hline First author & $\begin{array}{l}\text { Total \# } \\
\text { patients }\end{array}$ & Cure (\%) & Recurrence (\%) \\
\hline Blevins [1] & 9 & 44 (microadenomas) & \\
& 4 & 0 (macroadenomas) & 25 \\
Ram [32] & 17 & 71 & \\
Swearingen [37] & 28 & 46 & \\
Locatelli [20] & 12 & 67 & \\
\hline
\end{tabular}

favor repeat surgery for patients who have a majority of their tumor located within the cavernous sinuses or in other surgically inaccessible regions. Patients with microadenomas that are either visualized on MRI or else suspected to be present based on the results of inferior petrosal sinus sampling are considered for repeat surgery, especially when an inexperienced neurosurgeon performed the initial procedure. Approximately one-half to three-quarters of patients with microadenomas can be expected to enter remission following repeat surgery when performed by an experienced neurosurgeon (Table 5).

\section{The efficacy of radiotherapy}

Radiotherapy has long been used in the management of patients with Cushing's disease who were failed by pituitary surgery [29].

Fractionated conventional external beam radiotherapy has been utilized extensively and is generally well tolerated. Remission can be expected in about $50 \%$ of adults and $80 \%$ of children [29, 30]. Unfortunately, the response to treatment is delayed; only $50 \%$ of patients enter remission 18 months after treatment. Normalization of cortisol secretion may occur between 6 and 60 months [7, 21, 41].

Stereotactic radiosurgery, most commonly in the form of Gamma $\mathrm{Knife}^{\circledR}$ radiosurgery, has been increasingly employed in the management of patients with pituitary tumors in attempt to minimize unintentional irradiation to local neural and vascular structures while delivering a high dose of radiation precisely focused on the target tumor volume. The successful normalization of cortisol levels in 27$66 \%$ of adult patients is comparable to that observed when conventional external radiotherapy is employed [4, 11, 16, $17,19,21,24,26,29,35,41]$. The mean time to normalization of cortisol levels however is much shorter, occurring on average in 6-8 months, with a reported range of 636 months $[4,5,16,24-26,35]$. This observation suggests that while stereotactic radiosurgery is not necessarily more efficacious than conventional external radiotherapy, it does normalize cortisol levels more quickly and therefore limits the exposure to hypercortisolemia and its consequences.

Stereotactic radiosurgery appears to provide control of tumor burden in $66-98 \%$ of patients. Data on recurrence rates are rare in the literature, though rates reported are less than $10 \%[12,21,35]$. In contrast, recurrence rates following conventional external radiotherapy are reported to be as high as $45 \%$ with relapses occurring as late as 84 months following therapy [12, 19].

Potential late sequelae of either type of radiation therapy include hypopituitarism, radiation-induced optic neuropathy, temporal lobe necrosis, and secondary carcinogenesis. The reported incidence of optic neuropathy and temporal lobe necrosis with stereotactic neurosurgery is less than $2 \%$ and between $1 \%$ and $5 \%$, respectively; only isolated cases of secondary neoplasms have been reported in the literature [29]. In contrast, there is an estimated two-fold increased risk of developing a second neoplasm following conventional external radiotherapy. Pituitary hormone deficiencies are reported with both modalities in one- to two-thirds of patients as late as 10 years post-treatment [4, 12, 18, 35].

We only employ radiotherapy in the management of patients with persistent Cushing's disease when we have confirmed the pituitary as the site of ACTH hypersecretion. We employ stereotactic radiosurgery whenever possible and especially in younger patients. Suitable patients for stereotactic radiosurgery include those with a demonstrable lesion on MRI, those with intrasellar microadenomas identified on MRI preoperatively and histologic evidence of tumors at the time of surgery regardless of whether tumors are seen on postoperative imaging studies, and those who have cavernous sinus or bony invasion in patterns that permit treatment planning such that the optic pathways and other neural and vascular structures will not receive an inappropriate amount of radiation. Patients with suprasellar lesions in close proximity to the optic pathways are generally referred for conventional radiotherapy. Patients with invasive macroadenomas are probably best treated with conventional radiotherapy unless a region of interest for treatment can be developed to encompass the entire original tumor bed in order to permit irradiation of residual microscopic invasive tumor.

\section{Medical therapy to lower cortisol levels}

A number of steroid biosynthesis inhibitors can be employed in order to gain control of hypercortisolism. 
These drugs are particularly useful to improve the overall health status of patients in the event that repeat surgery will be delayed by more than $4-8$ weeks and while awaiting the beneficial effects of radiotherapy.

We prefer to employ ketoconazole as first-line therapy. We initiate therapy with a dose of $200 \mathrm{mg}$ twice daily. The dose is escalated as needed at $2-4$ week intervals to a maximum dose of $400 \mathrm{mg}$ four times daily to achieve normal urinary cortisol excretion rates. Aminoglutethimide and metyrapone are useful, either alone or in combination with ketoconazole, when cortisol levels are refractory to treatment or the side effects of ketoconazole are intolerable. These medications are becoming increasingly difficult to obtain by prescription. We prescribe mitotane as a drug of last resort in patients with Cushing's disease. We have found that most patients will not tolerate the side effects of the drug even when the medication is scheduled in a fashion to limit toxicity. Regardless of the drug employed, surveillance of urinary cortisol excretion rates at regular intervals is necessary in order to identify those refractory to treatment, those who suffer from breakthrough hypercortisolism, and also to detect hypocortisolism in those who may have responded to radiotherapy. In general, we discontinue medical therapy for 6 weeks to permit reassessment of cortisol excretion rates in patients who have been treated with radiotherapy when their 24-h urinary cortisol levels are in or even below the lower quartile of the normal range in the assay employed.

\section{Bilateral adrenalectomy in the management of refractory patients}

Bilateral adrenalectomy should definitely be employed when all else has failed and the patient is in grave danger due to the consequences of hypercortisolism [9, 28]. The relative success and lower risk of complications from laparoscopic bilateral adrenalectomy indicates that this therapeutic modality might be employed earlier in the course of treatment for some patients with Cushing's disease. Still, a decision to recommend adrenalectomy is not to be taken lightly as the operative mortality approaches $5 \%$ and as many as $20 \%$ of patients suffer from perioperative complications including deep vein thrombosis, delayed wound healing, bleeding disorders, and perioperative infections [15]. Nelson's syndrome develops after bilateral adrenalectomy in approximately one-fifth of patients and may require additional therapeutic intervention directed at the enlarging pituitary tumor. It is generally accepted that the risk of developing Nelson's syndrome following adrenalectomy can be reduced by one-half by delivery of conventional or stereotactic radiotherapy to the pituitary tumor prior to adrenalectomy.

\section{Conclusions}

In conclusion, we recommend an individualized approach to the evaluation and management of the patient with residual Cushing's disease following initial pituitary surgery. Decisions regarding the need for additional treatment are based on the status of the disease activity and confirmation of the original diagnosis based upon a review of the results of endocrine tests and histopathology as well as postoperative radiological studies. The expertise and capabilities of treating physicians as well as the availability of modalities that can be employed to deliver alternative therapies should be considered. Complex patients should be referred to a tertiary medical center for management by an experienced multi-disciplinary team in patients who have persistent or recurrent hypercortisolism.

Open Access This article is distributed under the terms of the Creative Commons Attribution Noncommercial License which permits any noncommercial use, distribution, and reproduction in any medium, provided the original author(s) and source are credited.

\section{References}

1. Blevins LS Jr, Christy JH, Khajavi M, Tindall GT (1998) Outcomes of therapy for Cushing's disease due to adrenocorticotropin-secreting pituitary macroadenomas. J Clin Endocrinol Metab 83:63-67. doi:10.1210/jc.83.1.63

2. Bochicchio D, Losa M, Buchfelder M (1995) Factors influencing the immediate and late outcome of Cushing's disease treated by transsphenoidal surgery. A retrospective study by the European Cushing's Disease Survey Group. J Clin Endocrinol Metab 80:3114-3120. doi:10.1210/jc.80.11.3114

3. De Tommasi C, Vance ML, Okonkwo DO, Diallo A, Laws ER Jr (2005) Surgical management of adrenocorticotropic hormonesecreting macroadenomas: outcome and challenges in patients with Cushing's disease or Nelson's syndrome. J Neurosurg 103: $825-830$

4. Degerblad M, Rahn T, Bergstrand G, Thoren M (1986) Longterm results of stereotactic radiosurgery to the pituitary gland in Cushing's disease. Acta Endocrinol (Copenh) 112:310-314

5. Devin JK, Allen GS, Cmelak AJ, Duggan DM, Blevins LS (2004) The efficacy of linear accelerator radiosurgery in the management of patients with Cushing's disease. Stereotact Funct Neurosurg 82:254-262. doi:10.1159/000083476

6. Esposito F, Dusick JR, Cohan P, Moftakhar P, McArthur D, Wang $\mathrm{C}$ et al (2006) Clinical review: Early morning cortisol levels as a predictor of remission after transsphenoidal surgery for Cushing's disease. J Clin Endocrinol Metab 91:7-13. doi:10.1210/jc. 2005-1204

7. Estrada J, Boronat M, Mielgo M, Magallon R, Millan I, Diez S et al (1997) The long-term outcome of pituitary irradiation after unsuccessful transsphenoidal surgery in Cushing's disease. N Engl J Med 336:172-177. doi:10.1056/NEJM199701163360303

8. Estrada J, Garcia-Uria J, Lamas C, Alfaro J, Lucas T, Diez S et al (2001) The complete normalization of the adrenocortical function as the criterion of cure after transsphenoidal surgery for Cushing's disease. J Clin Endocrinol Metab 86:5695-5699. doi:10.1210/ jc.86.12.5695 
9. Favia G, Boscaro M, Lumachi F, D'Amico DF (1994) Role of bilateral adrenalectomy in Cushing's disease. World J Surg 18:462-466. doi:10.1007/BF00353737

10. Hammer GD, Tyrrell JB, Lamborn KR, Applebury CB, Hannegan ET, Bell S et al (2004) Transsphenoidal microsurgery for Cushing's disease: initial outcome and long-term results. J Clin Endocrinol Metab 89:6348-6357. doi:10.1210/jc.2003-032180

11. Hayashi M, Izawa M, Hiyama H, Nakamura S, Atsuchi S, Sato H et al (1999) Gamma Knife radiosurgery for pituitary adenomas. Stereotact Funct Neurosurg 72(Suppl 1):111-118. doi:10.1159/ 000056446

12. Hoybye C, Grenback E, Rahn T, Degerblad M, Thoren M, Hulting AL (2001) Adrenocorticotropic hormone-producing pituitary tumors: 12- to 22-year follow-up after treatment with stereotactic radiosurgery. Neurosurgery 49:284-291 (discussion 291-282)

13. Imaki T, Tsushima T, Hizuka N, Odagiri E, Murata Y, Suda T et al (2001) Postoperative plasma cortisol levels predict longterm outcome in patients with Cushing's disease and determine which patients should be treated with pituitary irradiation after surgery. Endocr J 48:53-62. doi:10.1507/endocrj.48.53

14. Invitti C, Giraldi FP, de Martin M, Cavagnini F, Study Group of the Italian Society of Endocrinology on the pathophysiology of the hypothalamic-pituitary-adrenal or axis (1999) Diagnosis and management of Cushing's syndrome: results of an Italian multicentre study. J Clin Endocrinol Metab 84:440-448. doi:10.1210/ jc. 84.2 .440

15. Jenkins PJ, Trainer PJ, Plowman PN, Shand WS, Grossman AB, Wass JA et al (1995) The long-term outcome after adrenalectomy and prophylactic pituitary radiotherapy in adrenocorticotropindependent Cushing's syndrome. J Clin Endocrinol Metab 80: 165-171. doi:10.1210/jc.80.1.165

16. Kim SH, Huh R, Chang JW, Park YG, Chung SS (1999) Gamma Knife radiosurgery for functioning pituitary adenomas. Stereotact Funct Neurosurg 72(Suppl 1):101-110. doi:10.1159/000056445

17. Kobayashi T, Kida Y, Mori Y (2002) Gamma knife radiosurgery in the treatment of Cushing disease: long-term results. J Neurosurg 97:422-428

18. Kokubo M, Sasai K, Shibamoto Y, Aoki T, Oya N, Mitsumori M et al (2000) Long-term results of radiation therapy for pituitary adenoma. J Neurooncol 47:79-84. doi:10.1023/A:1006450024305

19. Littley MD, Shalet SM, Beardwell CG, Ahmed SR, Sutton ML (1990) Long-term follow-up of low-dose external pituitary irradiation for Cushing's disease. Clin Endocrinol (Oxf) 33:445-455. doi:10.1111/j.1365-2265.1990.tb03883.x

20. Locatelli M, Vance ML, Laws ER (2005) Clinical review: the strategy of immediate reoperation for transsphenoidal surgery for Cushing's disease. J Clin Endocrinol Metab 90:5478-5482. doi: 10.1210/jc.2004-2436

21. Mahmoud-Ahmed AS, Suh JH (2002) Radiation therapy for Cushing's disease: a review. Pituitary 5:175-180. doi:10.1023/ A: 1023365200437

22. Mampalam TJ, Tyrrell JB, Wilson CB (1988) Transsphenoidal microsurgery for Cushing disease. A report of 216 cases. Ann Intern Med 109:487-493

23. McCance DR, Gordon DS, Fannin TF, Hadden DR, Kennedy L, Sheridan B et al (1993) Assessment of endocrine function after transsphenoidal surgery for Cushing's disease. Clin Endocrinol (Oxf) 38:79-86. doi:10.1111/j.1365-2265.1993.tb00976.x

24. Mitsumori M, Shrieve DC, Alexander EIII, Kaiser UB, Richardson GE, Black PM et al (1998) Initial clinical results of LINAC-based stereotactic radiosurgery and stereotactic radiotherapy for pituitary adenomas. Int J Radiat Oncol Biol Phys 42:573-580. doi:10.1016/ S0360-3016(98)00256-9
25. Mokry M, Ramschak-Schwarzer S, Simbrunner J, Ganz JC, Pendl G(1999) A six year experience with the postoperative radiosurgical management of pituitary adenomas. Stereotact Funct Neurosurg 72(Suppl 1):88-100. doi:10.1159/000056444

26. Morange-Ramos I, Regis J, Dufour H, Andrieu JM, Grisoli F, Jaquet $P$ et al (1998) Short-term endocrinological results after gamma knife surgery of pituitary adenomas. Stereotact Funct Neurosurg 70(Suppl 1):127-138. doi:10.1159/000056415

27. Nakane T, Kuwayama A, Watanabe M, Takahashi T, Kato T, Ichihara $\mathrm{K}$ et al (1987) Long term results of transsphenoidal adenomectomy in patients with Cushing's disease. Neurosurgery 21:218-222. doi:10.1097/00006123-198708000-00015

28. O'Riordain DS, Farley DR, Young WF Jr, Grant CS, van Heerden JA (1994) Long-term outcome of bilateral adrenalectomy in patients with Cushing's syndrome. Surgery 116:1088-1093 (discussion 1093-1084)

29. Orth DN (1995) Cushing's syndrome. N Engl J Med 332:791-803. doi:10.1056/NEJM199503233321207

30. Orth DN, Liddle GW (1971) Results of treatment in 108 patients with Cushing's syndrome. N Engl J Med 285:243-247

31. Pereira AM, van Aken MO, van Dulken H, Schutte PJ, Biermasz NR, Smit JW et al (2003) Long-term predictive value of postsurgical cortisol concentrations for cure and risk of recurrence in Cushing's disease. J Clin Endocrinol Metab 88:5858-5864. doi: 10.1210/jc.2003-030751

32. Ram Z, Nieman LK, Cutler GB Jr, Chrousos GP, Doppman JL, Oldfield EH (1994) Early repeat surgery for persistent Cushing's disease. J Neurosurg 80:37-45

33. Saeger W (1991) Surgical pathology of the pituitary in Cushing's disease. Pathol Res Pract 187:613-616

34. Scheithauer BW, Kovacs KT, Laws ER Jr, Randall RV (1986) Pathology of invasive pituitary tumors with special reference to functional classification. J Neurosurg 65:733-744

35. Sheehan JM, Vance ML, Sheehan JP, Ellegala DB, Laws ER Jr (2000) Radiosurgery for Cushing's disease after failed transsphenoidal surgery. J Neurosurg 93:738-742

36. Sonino N, Zielezny M, Fava GA, Fallo F, Boscaro M (1996) Risk factors and long-term outcome in pituitary-dependent Cushing's disease. J Clin Endocrinol Metab 81:2647-2652. doi:10.1210/jc.81. 7.2647

37. Swearingen B, Biller BM, Barker FGII, Katznelson L, Grinspoon S, Klibanski A et al (1999) Long-term mortality after transsphenoidal surgery for Cushing disease. Ann Intern Med 130: $821-824$

38. Toms GC, McCarthy MI, Niven MJ, Orteu CH, King TT, Monson JP (1993) Predicting relapse after transsphenoidal surgery for Cushing's disease. J Clin Endocrinol Metab 76:291-294. doi: 10.1210/jc.76.2.291

39. Trainer PJ, Lawrie HS, Verhelst J, Howlett TA, Lowe DG, Grossman AB et al (1993) Transsphenoidal resection in Cushing's disease: undetectable serum cortisol as the definition of successful treatment. Clin Endocrinol (Oxf) 38:73-78. doi:10.1111/ j.1365-2265.1993.tb00975.x

40. Yap LB, Turner HE, Adams CB, Wass JA (2002) Undetectable postoperative cortisol does not always predict long-term remission in Cushing's disease: a single centre audit. Clin Endocrinol (Oxf) 56:25-31. doi:10.1046/j.0300-0664.2001.01444.x

41. Yoon SC, Suh TS, Jang HS, Chung SM, Kim YS, Ryu MR et al (1998) Clinical results of 24 pituitary macroadenomas with linacbased stereotactic radiosurgery. Int J Radiat Oncol Biol Phys 41: 849-853. doi:10.1016/S0360-3016(98)00124-2 